University of Nebraska - Lincoln

DigitalCommons@University of Nebraska - Lincoln

2000

Striving to do well what comes naturally: Social support, developmental psychopathology, and social policy

Ross A. Thompson

University of Nebraska-Lincoln

Lenna Ontai

University of Nebraska-Lincoln

Follow this and additional works at: https://digitalcommons.unl.edu/psychfacpub

Part of the Psychiatry and Psychology Commons

Thompson, Ross A. and Ontai, Lenna, "Striving to do well what comes naturally: Social support, developmental psychopathology, and social policy" (2000). Faculty Publications, Department of Psychology. 340.

https://digitalcommons.unl.edu/psychfacpub/340

This Article is brought to you for free and open access by the Psychology, Department of at DigitalCommons@University of Nebraska - Lincoln. It has been accepted for inclusion in Faculty Publications, Department of Psychology by an authorized administrator of DigitalCommons@University of Nebraska - Lincoln. 


\title{
Striving to do well what comes naturally: Social support, developmental psychopathology, and social policy
}

\author{
ROSS A. THOMPSON AND LENNA ONTAI \\ University of Nebraska
}

\begin{abstract}
Social support can have significant stress-preventive and stress-buffering benefits for troubled individuals in everyday circumstances. Consequently, it is not surprising that many therapeutic and preventive programs enlist social support to address problems of child and family psychopathology, especially in the context of "two-generation interventions" that seek to improve child well-being by strengthening parental functioning and parent-child relationships. Home visitation programs are the best known of these two-generation strategies and have become the focus of state-level and national efforts to support families and prevent harm to children. The conclusions of basic research studies on social support converge significantly with the findings of evaluation studies of the impact of home visitation programs to yield important new insights into the conditions in which formal social support is likely to be beneficial, or ineffective, in improving child and family well-being. Both basic and applied research literatures emphasize the importance of linking formal social support to informal social networks in extended families, neighborhoods, and communities, and attending to the complex reactions of the recipients of support and the needs of support providers. These studies are reviewed and evaluated to highlight the connections between social support, developmental psychopathology, and social policy.
\end{abstract}

In everyday circumstances, children and adults enjoy considerable social support from family, neighbors, and friends at school or work. We commonly rely on these people for advice, information, material assistance, and emotional stability, especially when life is difficult. People in distress are, in fact, especially reliant on social support because of the friendship, tangible guidance, material aid, and objective perspective that others can provide.

Unfortunately, individuals most in need of social support are often the most isolated. Their need and distress may be a deterrent to obtaining aid from others, and their life circumstances may separate them from contact with people who can be of assistance. This is especially true of children and adolescents

Address correspondence and reprint requests to: Ross A. Thompson, Department of Psychology, University of Nebraska, 238 Burnett Hall, Lincoln, NE 68588-0308. with psychological problems, whose symptomatology often causes them to be isolated within their families and peer groups, and who live in families that are often troubled and withdrawn from the neighborhood and community. As a consequence, the potential benefits that natural avenues of social support might afford to the prevention and treatment of developmental psychopathology are unavailable to many young people, or to their families.

There has been considerable enthusiasm in recent years for prevention and treatment programs that incorporate social support interventions, recognizing that the counseling, information, guidance, and networking that constitute the everyday benefits of social support can have many positive consequences for troubled children, youth, and families. There are many, many kinds of intervention programs incorporating social support using di- 
verse models of assistance, including home visitation programs, group therapy for children and adolescents, child-care-based parent support groups, social skills training programs, peer counseling initiatives, intensive family preservation interventions, parent education programs involving peers (such as Parents as Teachers), therapeutic preschool programs, and many other program models and strategies. The goals of these supportive interventions are equally diverse, including developmental remediation and therapy, preventing child maltreatment, strengthening parenting skills, improving parent-child relationships, enhancing child or parental emotional wellbeing, and promoting family health and economic self-sufficiency. The breadth and diversity of intervention initiatives that incorporate social support suggests that the issue is not whether mental health treatment or prevention programs incorporate social support (even traditional inpatient therapeutic services incorporate some social support features). Rather, the central question is how much social support goals are incorporated into and integrate the services and goals of an intervention program. This reflects, in some respects, the extent to which the value of social support is widely recognized.

Despite widespread confidence in the benefits of social support, however, there has been considerable reassessment in recent years of the efficacy of intervention programs for children and families, especially interventions in which social support is a prominent feature, such as home visitation and family support initiatives (e.g., Barnes, Goodson, \& Layzer, 1995, 1996; Cowan, Powell, \& Cowan, 1998; Gomby, Culross, \& Behrman, 1999; Guralnick, 1997; Halpern, 2000; Larner, Halpern, \& Harkavy, 1992; Margie \& Phillips, 1999; Thompson, 1995). This reassessment derives from the disappointing results of evaluation studies: many welldesigned programs have failed to show substantial improvements in child or family functioning that endure over time. These findings have been surprising, and reveal how difficult it can be to alter the psychological functioning of multiproblem families, or the children within those families, through interventions that rely primarily on social support. The emerging conclusion from these studies is that although supportive interventions can be valuable, providing social support to needy recipients is easy in abstract but difficult in practice, and must be combined with other forms of assistance. More specifically, intervention effectiveness is crucially mediated by considerations such as the origins, background and training of helpers, the engagement and responses of recipients, clarity in program goals and expectations for intervention, connecting recipients to other services and resources, attention to the unique needs of different recipient populations, how support is viewed in the neighborhood and community, and strategies to foster continuing social support to children and families after the program has ended. Without attention to these issues, well-meaning efforts to offer social support to children and families are likely to founder.

The purpose of this article is to profile the connections between social support and the effective prevention and treatment of developmental psychopathology, and to outline the implications for social policy. Rather than reviewing specific supportive programs oriented toward particular behavioral disorders, our goal is instead to address a series of central questions. What is social support? How is it relevant to child clinical disorders? What accounts for the impact of helping relationships on psychological well-being? Why are social support efforts effective, and sometimes ineffective? We believe that considering these questions thoughtfully reveals why social support is an attractive, but sometimes impotent, feature of efforts to assist troubled children and families.

Then we focus on one well-known social support intervention to improve child and family functioning-home visitation programs - to derive more specific lessons concerning the ingredients of successful supportive programs. Home visitation was also chosen because this strategy has become the basis for large-scale efforts to strengthen healthy family functioning and prevent dysfunction that have been supported by state and local policymakers. Moreover, a national network of home visitation programs, the 
Healthy Families America initiative, reflects continuing efforts to achieve one of the central goals of the U.S. Advisory Board on Child Abuse and Neglect (a Congressionally mandated commission) to achieve a childcentered, neighborhood-based national child protection system. Home visitation is thus one way that social support interventions are relevant to social policy. In a concluding note, we consider what the research on social support means for social policies intended to benefit troubled children and their families, and the implications for future research.

\section{What Is Social Support? Why Is It Important?}

In the broadest sense, social support is believed to have both stress-preventive and stress-buffering features (Cohen \& Wills, 1985; House, Umberson, \& Landis, 1988; Vaux, 1988). On one hand, social support surrounds individuals with emotional and instrumental assistance that promotes well-being. On the other hand, social support reduces the toll of stressful events by contributing to effective coping. The dual stress-preventive and stress-buffering functions of social support highlight three reasons why social support may be a valuable contributor to the prevention and treatment of developmental psychopathology.

First, social support interventions can contribute to the treatment of troubled children. As parents, peers, teachers, and extended family members can attest, psychological problems in childhood and adolescence are marked by impaired social functioning. Children suffering from emotional problems have difficulty forming and maintaining supportive relationships, and their behavior may also repel others and deter the social support they need. There are many examples of this. The aggression, destructiveness, and disregard for others' feelings of children with conduct disorders is one illustration of how clinical conditions are tied to social dysfunction (Dishion, French, \& Patterson, 1995). Another is the withdrawn, distrustful, and self-denigrating tendencies of depressed children, which can isolate them within the family and the peer culture (Cicchetti \& Toth, 1995). Children with anxiety disorders become hypervigilant to fear-provoking situations and preoccupied with the visceral cues of anxiety, and these characteristics are socially dysfunctional (Albano, Chorpita, \& Barlow, 1996). Indeed, most conditions of developmental psychopathology place children at risk of social isolation or social dysfunction owing to their behavioral problems. Insofar as supportive, positive relationships contribute to healthy development, these clinical problems can lead to self-perpetuating difficulty because of the social support they inhibit. Social support, whether in the context of group therapy, peer counseling, social skills training, a therapeutic preschool or classroom, or an alternative approach, can contribute to restoring positive social skills, enhancing positive social motivation, improving self-esteem, and thus enabling the natural sources of everyday support that contribute to healthy psychological growth. In these ways, support buffers the impact of clinical psychopathology.

Second, social support interventions can contribute to the prevention of psychological problems. For many children, relational difficulty-especially within the family-is an important determinant of whether intrinsic vulnerability becomes a psychopathological condition or not. Hostile or disinterested parenting is a risk factor for the development of disruptive behavior problems during the preschool years, for example, along with temperamental vulnerability (Shaw, Keenen, \& Vondra, 1994; Shaw, Owens, Vondra, Keenan, \& Winslow, 1996). Antisocial behavior can emerge developmentally from enduring patterns of mutually coercive parent-child interactions in which each partner negatively reinforces the demanding behavior of the other (Patterson, DeBaryshe, \& Ramsey, 1989; Patterson, Reid, \& Dishion, 1992). The same behaviors can, when generalized to the peer group, lead to the child's rejection by other children. Anxiety disorders have developmental origins in insecure or difficult parentchild relationships as well as inhibited temperament. A parent's anxious, denigrating, overinvolved, or otherwise inappropriate response to a child's anxiety is significantly re- 
lated to the onset of pathology (Hirshfeld, Rosenbaum, Smoller, Fredman, \& Bulzacchelli, 1998; Thompson, in press). Criticism, hostility, and rejection by family members (i.e., "expressed emotion") is strongly linked to schizophrenic sympatomatology (Goldstein, 1987; Kavanagh, 1992). In each instance, vulnerability to psychopathology is enhanced by dysfunctional relationships in the family.

Moreover, some family environments are psychologically damaging to children regardless of whether children have intrinsic vulnerabilities to psychopathology. Children growing up in homes characterized by marital conflict (Cummings \& Davies, 1994; Davies \& Cummings, 1994), domestic violence (Carter, Weithorn, \& Behrman, 1999; Edelson, 1999), psychological abuse (Hart, Brassard, \& Karlson, 1996; Thompson \& Wyatt, 1999), the parent's affective disorder (Dawson, Hessl, \& Frey, 1994; Zahn-Waxler \& Kochanska, 1990), and other conditions also experience considerable risk for the development of psychopathology. In these settings, children's capacities for emotion regulation are taxed by the potentially overwhelming and inconsistent emotional demands upon them (Thompson \& Calkins, 1996; Thompson, Flood, \& Lundquist, 1995). Social support from extended kin, neighbors, formal helpers (such as social workers or therapists), or others can help to change difficult patterns of parent-child interaction or dysfunctional parental behavior. This can occur as helpers model and reinforce more appropriate relational patterns, provide an outlet for stress that may otherwise be expressed in harm to children, and encourage developmentally appropriate expectations for offspring. In these ways, social support-whether it occurs through natural social networks or in the context of parent education or peer support interventions-contributes preventively to children's psychological health. At the same time, helpers can sometimes offer children within these families an alternative source of emotional assistance, which can be a significant contributor to their adaptive resiliency in difficult family circumstances (Masten \& Coatsworth, 1995).
Third, social support interventions are important because the social isolation of troubled families can be a risk factor for child maltreatment and other problems. There are many reasons that troubled families become isolated within their communities, including (a) their marginalization and, sometimes, stigmatization owing to problems of poverty, substance abuse, mental illness, or other difficulties; (b) their inability or unwillingness to maintain social networks because of stress, distrust, or humiliation; (c) the fragmentation and disorganization of the neighborhoods within which they live; or (d) the active efforts of family members to escape detection of their abusive or neglectful parenting (Thompson, 1995). Social support interventions can offer many benefits to these families. Formal or informal support can reduce the marginalization and distrust of family members, strengthen their social skills and parenting practices, motivate them to become engaged with others, and provide access to other services, material aid, or information they need. Moreover, social support can also be enlisted to monitor children's well-being to ensure that abuse or neglect is promptly detected.

In light of these diverse benefits, it is apparent that social support is a surprisingly multifaceted phenomenon. It has many features, including emotional aid, counseling and guidance, access to information and services, material assistance, sharing of tasks and responsibilities, and skill acquisition. When social support is enlisted in the context of developmental psychopathology, moreover, it incorporates added functions. These include monitoring the well-being of children, changing parental conduct, offering children access to extrafamilial sources of assistance, improving parent-child interaction and communication, strengthening adaptive capabilities (like social skills), developmental remediation, and integrating families into the community and the broader social networks of school, workplace, and the extended family. Because of the multiple needs of troubled families, social support interventions must often address many different needs for family members. 
One reason that social support can be ineffective, therefore, is that any social support intervention may have difficulty integrating these multiple, yet potentially inconsistent, family needs. This is, in fact, what those who try to assist troubled families often discover. Many at-risk families are distrustful of professional helpers, for example, because they realize that although these individuals may offer emotional support and material aid, they may also report family members to the authorities for illegal behavior, such as substance abuse or child maltreatment (Thompson, 1995). But these multiple responsibilities of helpers are essential to child protection. Many informal helpers also find that, in their efforts to assist troubled parents, it is far easier to provide emotional support than it is to challenge or change parental conduct, even though the latter is more critical to aiding offspring within the family. Korbin's $(1989,1995)$ study of mothers convicted of fatal child abuse revealed, for example, that family members, friends, and neighbors typically overlooked signs of parental dysfunction, minimized the seriousness of abuse, and offered reassurance about the mothers' good intentions in their efforts to offer noncritical emotional affirmation. In doing so, of course, they contributed little to curbing abusive practices. Thus, it can be difficult to harmonize all of the goals in providing social support. Often recipients prefer helpers to offer unconditional emotional support without challenging or changing their conduct.

Additional challenges to the effectiveness of social support interventions arise because the needs of children and parents must each be considered. Although children are usually the focus of concern, access to children must be achieved through parents who may feel very ambivalent about supportive interventions (see O'Donnell \& Steuve, 1983; Parke \& Bhavnagri, 1989). A parent's denial, humiliation, defensiveness, feelings of vulnerability, or effort to hide illegal or inappropriate conduct can each pose formidable obstacles to a child's access to social support. They may also pose obstacles to integrating parents into efforts to promote the child's well-being.
Parental resistance can also undermine the child's trust and confidence in others outside the family who try to provide assistance. As a consequence, in addition to child-focused support it is also necessary to devise interventions that can aid children indirectly by improving parental functioning and the parentchild relationship. The latter strategy, also known as a "two-generation intervention," is exemplified by home visitation and parent education programs. Both child-focused and two-generation strategies are challenging to implement, but most of the programs discussed in this article are two-generation interventions because of the belief that in most families at risk, both parents and children need assistance.

Taken together, it is easy to understand why social support interventions often fall short of their goals when these interventions are expected to accomplish so much for troubled children and families. As Robinson and Garber (1995) have noted, there is currently no coherent theory of how social support should guide intervention efforts. This means that social support means different things to different people, with different (and sometimes vague and conflicting) expectations for how supportive interventions should be designed and what they can accomplish.

Because social support is a multifaceted construct, providing social support requires far more than creating a large social network. As the literature in developmental psychopathology amply indicates, individuals can be surrounded by a large network of individuals who are not supportive and do not contribute to psychosocial well-being. Effective support can be provided by a small number of close associates (Cohen \& Wills, 1984; Gottlieb, 1985). Moreover, Korbin's (1989) study of fatally abusive mothers indicates that individuals can enjoy emotional support from a broad network of friends and family which does not advance goals of family well-being. Thus social support interventions must seek to accomplish far more than simply increasing the size of a social network or the frequency of contact with other people, or making recipients feel good about themselves. Interventions 
must seek primarily to strengthen the constructive influence of natural and formal helpers on the behavior of parents and children.

\section{Social Support and Social Relationships: The Impact of Helping Relationships on Psychological Well-Being}

When does social support provide helpful assistance to troubled recipients? Why is it sometimes ineffective? Further understanding of the answers to these questions requires viewing social support in the context of the social relationships in which it is offered. Contemporary relationship theories highlight that relationships can be sources of support and affirmation, and also sources of stress and difficulty-sometimes at the same time (Berscheid \& Reis, 1998; Bowlby, 1988; Collins \& Laursen, 1999). Establishing relationships that can offer counseling and assistance requires also risking criticism, embarrassment, indebtedness, and privacy violations (Belle, 1982). Just as social relationships are complex and can have multifaceted influences, so also are the effects of social support diverse and contingent. This is especially apparent when social support is viewed in the context of social network membership, and the complex reactions of recipients and providers of assistance.

\section{Social support and social network membership}

Many people are potential helpers to another person in need. Within natural social networks, helpers can consist of friends, neighbors, extended family members, coworkers, teachers, or classmates. Formal helpers may include a social worker, religious advisor, paraprofessional home visitor, or peer counselor. Supportive relationships can be established with each of these individuals, but the kind of assistance each provides is defined, in part, by the nature of the relationship with the recipient.

Supportive relationships with natural social network members like neighbors and extended kin have many advantages, including their easy accessibility, each partner's sharing of congruent values and perspectives, their endurance over time, and their integration into various aspects of a recipient's life circumstances (Gottlieb, 1983). Within natural social networks, moreover, different partners can offer different kinds of assistance. A coworker can help with workplace demands, a neighbor can provide respite child care or material aid, and extended family can be counted on for advice during difficult times. However, natural social network partners also have disadvantages (Cochran, Larner, Riley, Gunnarsson, \& Henderson, 1990). Because they share the experience and perspectives of recipients, they may be less likely to challenge inappropriate conduct, and they may be overwhelmed by the same circumstances that challenge recipients (such as neighborhood danger or socioeconomic distress). This is especially likely to be true in neighborhoods that are drained of material and human capital, where many at-risk families live (Garbarino \& Sherman, 1980). In addition, stressful circumstances can also cause troubled families to become isolated within their natural social networks and may undermine an individual's capacity to obtain assistance from others because of fatigue, limited time, or hopelessness.

Formal helpers can overcome many of these disadvantages because of their professional training and resources, a specific role definition in relation to recipients, and professional accountability. But because they are less well integrated into the lives of recipient families, they may be unaware of many circumstances affecting their well-being. Formal helpers may also have difficulty engaging recipients in counseling, peer group activities, home visits, or other programmatic activities.

Consequently, integrating the efforts of formal helpers with those of natural helpers in recipients' social networks offers the best opportunities for enduring preventive or therapeutic benefits (Froland, Pancoast, Chapman, \& Kimboko, 1981; Miller \& Whittaker, 1988). This can occur in many ways. Formal and informal assistance is harmonized, for example, when a parent support group is organized around a local school or child care program, a perinatal home visitor encourages the company of extended kin during home visits, 
or a group therapy program for adolescents has connections to the school or to members of the peer group. The effective coordination of formal and informal support networks is not easy, however, because of the differences in background, values, goals, and definition of the problem that may provoke mutual distrust between formal and informal helpers. All too commonly, extended family members or neighbors reinforce a parent's skepticism of the potential helpfulness of a counselor or paraprofessional home visitor. Sometimes social workers undermine informal helpers by criticizing them or trying to assume their roles. But the integration of formal and informal helping is essential to promote the engagement of recipients in social support interventions and to provide a foundation for enduring assistance. Many well-meaning social support interventions fail because they do not sufficiently incorporate the natural helping networks of family members, resulting in assistance that is limited in time, scope, and impact.

\section{Recipient reactions to aid}

Obtaining assistance from another evokes mixed reactions from most recipients. In addition to the feelings of pleasure, relief, and gratitude that helping naturally inspires, recipients may also experience negative feelings for various reasons (Fisher, Nadler, \& Witcher-Alagna, 1982; Shumaker \& Brownell, 1984). Receiving help can be humiliating and stigmatizing, especially when helping derives from inadequacies in the recipient (such as poor parenting, chemical dependency, or inadequate personal or financial management) rather than from broader impersonal circumstances (such as a natural disaster). Receiving help can also inspire feelings of failure, indebtedness, and inferiority, especially when assistance cannot be repaid, because of cultural norms of equity and reciprocity (Greenberg \& Westcott, 1983). Moreover, if assistance cannot be reciprocated or compensated, the recipient may also experience vulnerability and dependency because receiving assistance from another violates norms of self-reliance and autonomy. It also often entails privacy violations as help givers become inti- mately acquainted with aspects of the recipient's life that are not normally disclosed to others.

As a consequence of these reactions, recipients may rather paradoxically begin to resent the assistance they receive and the person providing it. This is especially likely when assistance is obtained from formal helpers or strangers (with whom one does not share an ongoing relationship of mutual aid), nonprofessionals (from whom assistance is altruistically motivated, enhancing the salience of reciprocity and equity norms), and when the helper and recipient are from similar backgrounds and circumstances (when the inequity of the helping relationship is especially apparent). When recipients experience assistance as humiliating, demeaning, or intrusive, they are less likely to seek help in the future and are more likely to terminate a helping relationship if they are capable of doing so. This can help explain why the recipients of assistance, to the surprise of their benefactors, may be ungrateful, fail to become engaged in the helping relationship, are often inexplicably absent from scheduled meetings, do not return phone calls, and progressively make the relationship unworkable or unsatisfying.

This analysis has surprising implications for the provision of social support to troubled families. It suggests that assistance is more easily accepted when recipients have opportunities to reciprocate or repay the aid they receive, perhaps in service to other needy individuals. It suggests that support is more readily received in circumstances that minimize the potential for humiliation or stigmatization, such as when support services are broadly available or universal (rather than specifically targeted to those in greatest need) and accessed in everyday settings (rather than an agency office). This analysis suggests also that social support is better received when both the recipient and the provider agree about the need for assistance, and the reasons for the need. By contrast, assistance from others may be resented when it derives from another's judgment of the recipient's inadequacy or incompetency, and the recipient is an unwilling participant.

Characteristics of the recipient can mediate 
the effects of social support in other ways. The capabilities required to establish and maintain supportive social ties may be deficient in some troubled individuals owing to mental health or substance abuse problems, limited intelligence, or the effects of stress itself (Heller \& Swindle, 1983; Shinn, Lehmann, \& Wong, 1984). For some families, for example, the personal disorganization of parents becomes manifested in an inability to effectively organize home life, ensure children's physical well-being, and keep appointments with a help provider (Polansky, Chalmers, Buttenwieser, \& Williams, 1981; Seagull, 1987). For troubled children and adults, clinical psychopathology may undermine one's willingness or ability to maintain formal or informal supportive relationships. And, as noted earlier, stress can cause individuals to feel overwhelmed by life difficulties and to lack the time, energy, or hope to seek support from other people. This can be especially true when families at risk live in dangerous neighborhoods that undermine access to neighbors, extended family members, and even formal help providers (Eckenrode, 1983; Eckenrode \& Wethington, 1990).

Because social support is not passively received, these recipient characteristics can pose formidable barriers to interventions based on supportive social relationships. Indeed, one of the most intractable obstacles to the success of social support interventions is the limited engagement and participation of recipient families. This suggests that a careful analysis of recipient reactions to assistance are necessary. When resistance to obtaining assistance derives from feelings of indebtedness, humiliation, or dependency, the conditions of support should be changed to reduce these perceptions and enhance participation in supportive relationships. When supportive relationships are undermined by characteristics of the recipient, these problems must first be remedied, such as in a substance abuse treatment or a social skills training program (see Gaudin, Wodarski, Arkinson, \& Avery, 19901991, for an example). These are not easy tasks, however, because often the personal characteristics of recipients or the conditions of support that undermine accepting help are deeply rooted or enduring.

\section{The needs of support providers}

Social support is usually given and received in relationships characterized by mutuality and reciprocity. But for reasons earlier described, recipients may be unwilling or incapable of returning the affirmation and support they receive, and they may respond to help providers with resentment instead of gratitude. This can make providing social support a draining experience to formal helpers or members of natural social networks, contributing to their exhaustion or despair (Collins \& Pancoast, 1976; Shumaker \& Brownell, 1984).

The relationship between support providers and recipients can be difficult for other reasons also. Each may have different goals, with recipients seeking noncritical emotional affirmation and providers striving for changes in the recipient's behavior and attitudes. They may differ also in their views of the recipient's problems and the best solutions. For these reasons, it is common for providers and recipients each to feel frustrated by their relationship, and to feel "out of sync" or in conflict with the partner.

Because a one-way relationship of unreciprocated assistance is difficult to maintain, thoughtfully designed social support interventions must attend to the support needs of providers. Whether formal or informal helpers are enlisted, it is essential that they are offered appropriate training, guided supervision, affirmation of the value and importance of their role, and other forms of support. Absent these, the task of establishing and maintaining strong, helpful relationships with troubled family members is undermined by burnout and turnover among the helping staff.

\section{Conclusions}

When viewed within the complex fabric of social relationships, it is clear that efforts to provide social support do not guarantee beneficial outcomes. Instead, the effectiveness of social support for preventing or treating clini- 
cal disorders hinges critically on factors such as who provides support, what are the goals of doing so, how the recipient responds to this effort, and the broader community context in which this occurs. More specifically, this analysis (see also Thompson, 1995) suggests that social support interventions are most likely to be effective when:

- there are clear, well-defined goals in mobilizing social support that are based on a careful analysis of the needs of family members and how support agents can address these needs;

- the efforts of formal helpers and informal helpers within natural social networks are integrated and coordinated;

- social support interventions provide bridges to broader community resources that can offer recipients long-term assistance;

- the need for social support is normalized within the community, so that receiving assistance is not stigmatizing or humiliating;

- there are efforts to improve recipient reactions to accepting aid, which may include reducing feelings of vulnerability, failure, or inferiority by providing opportunities to reciprocate aid, promoting recipients' voluntary participation in social support interventions, and developing an environment of mutual respect; and

- help providers are themselves supported through continuing supervision, training, and other forms of assistance.

These conclusions indicate that social support is not a panacea for the challenges of child clinical disorders, but that thoughtfully designed interventions can be effective if they attend to the complexities of the human relationships through which support is provided.

\section{Home Visitation as a Social Support Intervention}

Social support has become a common strategy for preventing and treating psychological dis- orders. Social workers, therapists, counselors, youth advisors, educators, and other professional and nonprofessional helpers are well aware of the benefits of social support, although the conditions in which support is effective (and ineffective) are not always recognized. What would happen, however, if social support interventions became a central component of public policies intended to assist troubled children and families? In posing this question, we begin the transition from questions of social support and developmental psychopathology to issues of social policy.

During the past decade, home visitation programs have become the most enthusiastically recognized avenue of social support to needy families. Because the social isolation of many troubled families disconnects them from community services, child-rearing guidance, good health care, material aid, and counseling, the fundamental strategy uniting diverse home visitation efforts is the delivery of information, guidance, and support to families in their homes. Doing so overcomes some of the barriers these families face to obtaining needed services (such as lack of transportation or health insurance) and establishes a relationship of trust with a home visitor who can provide individualized support and assistance (Wasik, Bryant, \& Lyons, 1990; Wasik \& Roberts, 1994).

In addition to this attractively straightforward approach, enthusiasm for home visitation increased during the 1990s with reports from two large-scale home visitation projects-the Hawaii Healthy Start Program (Hawaii Department of Health, 1992) and the Elmira Prenatal/Early Infancy Project (Olds, 1988)_indicating that these programs yielded significant decreases in child maltreatment and improvement in health care and parent-child interaction in treatment groups. In 1990 the U.S. General Accounting Office (GAO, 1990) released a report identifying home visitation as "a promising strategy for delivering or improving access to early intervention services." Home visitation programs have blossomed nationwide, with one estimate that more than a half-million children are enrolled in home visitation programs for 
pregnant women and families with young children (Gomby et al., 1999).

Home visitation has also emerged as a national and statewide strategy for improving children's developmental outcomes. The U.S. Advisory Board on Child Abuse and Neglect has recommended home visitation as one of a package of strategies to create a "child-centered, neighborhood-based child protection system" that better serves troubled families and their children (U.S. Advisory Board on Child Abuse and Neglect, 1992, 1993a, 1993b; see also Melton, Thompson, \& Small, in press). At the same time, the Healthy Families America initiative, developed by the $\mathrm{Na}-$ tional Committee to Prevent Child Abuse, has established a nationwide consortium of 270 home visitation programs in 38 states serving more than 18,000 families, with each program designed to improve child and family wellbeing (Daro, in press; Daro \& Harding, 1999). There has also been considerable interest in other states, besides Hawaii, in initiatives that enlist home visitation as a publicly supported social support effort. The legislative language of Proposition 10 in California, for example, which earmarks millions of dollars from a special cigarette tax for early childhood programs, specifically identified home visitation as a promising strategy. A large number of home visitation programs are funded by direct legislative appropriation in many states, or by project grants from federal agencies, as central features of statewide efforts to strengthen child development and prevent developmental disorders, maltreatment, or other problems.

\section{Elements of home visitation programs}

One of the most appealing features of home visitation programs is their flexibility (although this is a liability when program evaluation is concerned). The flexibility in the design and implementation of home visitation is useful because of the variety of complex problems that threaten to overcome troubled families. Over time, home visitors seek to establish trusting relationships with family members, which allows them to learn about the individual challenges each family is facing and to tailor services to address these difficul- ties. While all home visitation programs share the common goal of improving family functioning and child development, program flexibility means that there can be considerable variability in services offered and their goals, the training and background of the home visitor, and the intensity of service delivery.

Historically, home visitation programs have been modeled on those of European countries as a source of prenatal support and services to the mothers of newborns (GAO, 1990). But the scope of program goals and services has expanded in this country. Currently, home visitation programs offer services that address a wide variety of goals, ranging from preventing premature birth to improving family health care to supporting academic success in school. The services typically offered by a home visitor can be equally varied. For example, in order to improve young children's health and development and strengthen families' economic self-sufficiency, the Nurse Home Visitation Program offers mothers prenatal health information, lessons on infant and child health (to foster better communication with health care providers), practical guidance in parent-child communication and interaction skills, child health screening, and efforts to link mothers to their communities (Olds, Henderson, Kitzman, Eckenrode, Cole, \& Tatelbaum, 1999). By contrast, Hawaii's Healthy Start Program focuses on immediate crisis resolution for atrisk families and, as home visitation progresses, offers parenting and child development education, modeling of appropriate interaction with children, assistance in developing problem solving skills, informal counseling, material aid, and help in linking family members to needed community services (Duggan, McFarlane, Windham, Rohde, Salkever, Fuddy, Rosenberg, Buchbinder, \& Sia, 1999). Each of these diverse services falls under the rubric of "social support," but they constitute very different constellations of support to needy families.

The background and training of home visitors also varies widely. Some programs use professionals, such as nurses, while others enlist paraprofessionals (with collegiate degrees) or individuals from the community who re- 
ceive specialized training. Some programs, including Hawaii Healthy Start and the Healthy Families America programs, use other specialized personnel for the initial screening of families. There is disagreement over whether professionals, paraprofessionals, or community members are the most appropriate home visitors. Olds and Kitzman (1990) argue that professional nurses are more effective in improving children's health-related outcomes, partly because their advice is perceived as more authoritative. But others believe that paraprofessionals and community members create less social distance and can better establish trusting relationships with family members. In addition, they may be more capable of addressing the unique culture and language of family members (Margie \& Phillips, 1999).

The frequency and intensity of service delivery also varies for home visitation programs depending, in part, on the level of risk of the target population. Visits can occur monthly, biweekly, or weekly and can vary in their duration. In a review of 224 home visitation programs, Olds and Kitzman (1993) found that over half the programs used weekly visits, while another $12 \%$ had biweekly visiting. With respect to the duration of services, $21 \%$ of the programs offered assistance for less than 6 months, and only 19\% provided services for more than 1 year. This may be due, in part, to variability among programs in when home visitation begins. Whereas the Nurse Home Visitation Program begins prenatally, Hawaii's Healthy Start is initiated shortly after birth, and other programs (such as the Comprehensive Child Development Program and the Parents as Teachers program) can begin later in the child's 1st year (St. Pierre \& Lazierre, 1999; Wagner \& Clayton, 1999). Taken together, participants in some home visitation programs receive weekly visits beginning prenatally for 2-3 years, while others receive services biweekly or monthly beginning after birth for less than 6 months. This creates considerable variability in the intensity of home visitation, and its impact.

Variability in program goals and service delivery, the background and training of home visitors, and the frequency and intensity of services can make it appear that "home visitation" is merely a broad conceptual rubric for a collection of programs united only by strategy and location. But by contrast with interventions that are highly structured, home visitation encourages tailoring goals, services, and duration to the particular needs of client families. This means that different home visitation models necessarily vary in their goals and strategies, and that individual programs within each general model are also likely to be different and diverse. In this respect, home visitation ideally approximates the kind of social support commonly found in natural social networks in which individuals offer troubled friends or neighbors what they need, how they need it, and when they need it.

\section{Evaluation of the impact of home visitation}

It is natural for program planners to seek to understand the impact of the interventions they design. When their interventions become part of public programs and social policy to aid troubled families, it is essential that they do so to ensure the wise investment of public funds.

There have been several reviews of evaluation studies of home visitation programs (see, e.g., Olds \& Kitzman, 1993), but the most recent and large-scale evaluation efforts have yielded the most influential, and somewhat startling, conclusions. Based on sophisticated evaluation studies of six of the most wellknown home visitation models that have been implemented nationally (including the Nurse Home Visitation Program, Hawaii Healthy Start Program, Healthy Families America, and Parents as Teachers), Gomby and colleagues (1999) described the findings as "sobering." Program benefits were found to be modest and inconsistent across program sites and were enjoyed by only a subset of the families who participated in the program, and programs failed to accomplish most, if not all, of the goals of the home visitation effort. The benefits of home visitation were modest regardless of whether parental behavior or child outcomes were considered. The results of a meta-analysis of home visitation evaluation 
studies yielded similar conclusions (Appelbaum \& Sweet, 1999). Based on these, the reviewers recommended "that any new expansion of home visiting programs be reassessed in light of the findings ... [and] that existing programs focus on program improvement, that practitioners and policymakers recognize the inherent limitations in home visiting programs and embrace more modest expectations for their success, and that home visiting services are best funded as part of a broad set of services for families and young children" (Gomby et al., 1999, p. 6).

This analysis focused on several features of program design that may contribute to the mixed and modest effects of home visitation on family functioning. The factors identified in these evaluation studies will be familiarespecially in light of the earlier discussion of social support and social relationships-and are affirmed by other evaluations of family support programs emphasizing social support (e.g., Halpern, 2000; Larner, Halpern, \& Harkavy, 1992). They include the ambivalent participation of recipients, the challenges of support providers, the need to develop community connections, and clarity in program goals and expectations.

Failures of family engagement and high attrition rates were significant problems for all of the programs reviewed, suggesting that these problems may be intrinsic to home visitation and are not a consequence of poor program implementation (Gomby et al., 1999). Between 10 and $25 \%$ of families invited to enroll in home visitation programs decline, raising questions about what kinds of families choose to participate in home visitation and which do not. Furthermore, between 20 and $67 \%$ of the families who have enrolled leave the programs before they end. The reasons this occurs are not well understood, and may be related to residential relocation and other normative events. But attrition may also be related to the ambivalent recipient reactions to assistance earlier described, especially if family members do not perceive that home visitation addresses their needs and concerns, or feel embarrassed, indebted, or vulnerable because of the services they receive. In these circumstances, their failure to participate for the full duration of the program may reflect lack of engagement or commitment to the program's goals.

Furthermore, even when families enroll and remain in home visitation programs they tend to receive only about half or fewer of the intended number of contacts with the home visitor. This, too, has been observed across the range of home visitation initiatives. This may also reflect parents' lack of engagement, the inability to juggle home visits with other obligations, or chaotic family circumstances that, in combination with home visitors' large caseloads, makes it unlikely that missed visits will be rescheduled (Gomby et al., 1999; Margie \& Phillips, 1999). Therefore, home visitation programs face formidable obstacles in enrolling and engaging recipient families and in delivering services to them. It is difficult, of course, to provide social support to recipients when contact is inconsistent or infrequent, especially when support depends on establishing a trusting relationship with a home visitor. Furthermore, child outcomes are unlikely to be improved if parents are inconsistent or grudging participants in home visitation.

The importance of this problem to the success of home visitation is revealed in findings that the intensity of services markedly influences program effectiveness: the families receiving more contacts benefited more from home visitation (GAO, 1990; Gomby et al., 1999). There is no research, however, to indicate the minimum number of contacts with a home visitor that is necessary to improve child or family functioning. Although program staff can contribute to overcoming problems of attrition by making strong efforts to maintain contact with participant families, the most important solutions may derive from involving parents earlier and more actively in the design of services. What do parents need, and how can their views be incorporated into the design of home visitation? Furthermore, there is little research into how recipient families regard their experiences with a home visitor, and studies on this topic might reveal the kinds of strategies and services that can strengthen their investment and engagement.

A second challenge to the effectiveness of home visitation is staffing and the delivery of 
services. Home visitors are crucial to the effectiveness of this intervention because they have direct contact with families, establish trusting relationships with family members, and are expected to properly deliver the intended curriculum of services. But lack of training and supervision, as well as high turnover rates, are consistently observed in most home visitation programs (GAO, 1990; Gomby et al., 1999). It is not uncommon for home visitors to report shorter visits than intended, broken appointments that are not rescheduled, or preoccupation with immediate family crises rather than the delivery of intended education or guidance during home visits. Furthermore, the high turnover of home visitors undermines the relationship between participants and the program, and this may be one contributor to the lack of family engagement.

It is not difficult to understand these problems in light of the needs of support providers earlier discussed. Home visitors have a challenging role, requiring personal warmth, problem-solving and organizational skills, and crisis management abilities, and must work alone and with challenging recipients. Additional challenges may occur when working with culturally or linguistically diverse families, at-risk populations, or parents who suffer from depression, domestic violence, or substance abuse (Margie \& Phillips, 1999). This underscores the need for extensive training and continuing support, especially when home visitors are community members or paraprofessionals. This also makes it apparent why burnout and turnover can occur, especially when home visitors are unpaid volunteers rather than paid staff, and have high caseloads (Thompson, 1995). However, personnel, training, and supervision costs account for most of the program expenses, and thus poorly or inconsistently funded home visitation programs are likely to scrimp on these essential features of service delivery.

The skills, training, and reliability of home visitors is directly tied to the quality and consistency of the services provided needy families. It is not surprising that services differ according to family needs, but several studies of home visitation show that the nature of the curriculum varies significantly according to the values and orientation of the home visitor (Baker, Piotrkowski, \& Brooks-Gunn, 1999; Wagner \& Clayton, 1999). At times, in other words, what actually occurs during home visitation may be much different than what program designers intended. There has been very little research that monitors the nature and quality of services provided recipient families, and the need for such studies is underscored by the problems of visitation frequency and participant attrition earlier discussed. The experience of home visitation may vary significantly for families with different visitors, even when each visitor is using the same program model. The family's experience of home visitation may thus abruptly shift if one home visitor is replaced by another.

In light of these problems, it may be important to explore new ways of providing support to home visitors, perhaps in the context of teams of home visitors who share the responsibilities of working with challenging families. Using novel strategies like these, it might be possible to offer reliable, effective social support to troubled families without draining the psychological resources of help providers.

A third challenge to the effectiveness of home visitation is the need to develop strong connections between families and the broader community. As earlier noted, the success of formal helpers such as a home visitor depends, in part, on whether natural sources of social support can be enlisted on behalf of family members to provide ongoing, continuing assistance after home visitation has ended. By contrast with the traditional social work model, the home visitation approach recognizes that the home visitor cannot do it all, and consequently one of the significant goals of intervention must be to help families forge links within their communities to individuals and agencies that can provide long-term support. But while some programs explicitly target the broadening of community contacts, many home visitation programs do not establish this as a central goal, relying instead on referrals on a need-by-need basis.

Embedding home visitation in the local community is significant for other reasons that may contribute to its success. The re- 
sponses of family members to home visits are based, in part, on cultural values that may cause some families to be embarrassed or resistant to regular visits at home from a stranger, and knowledge of these cultural values can ease access to target populations. Moreover, understanding the culture (and language) of recipients is crucial to understanding how parents regard acceptable parenting practices and their beliefs about children and the family, and this understanding is essential to providing guidance that parents will find meaningful (Margie \& Phillips, 1999). Furthermore, the visibility and positive regard for a home visitation program within a community can contribute considerably to a program's success by improving family engagement and strengthening the connections between family members and their neighbors, school-based services, and other community agencies. Finally, community embeddedness is important for understanding what resources a neighborhood has to offer needy families and the extent to which the community is rich or poor in human and material capital. For all of these reasons, it is unfortunate that home visitation programs have not placed a higher priority on strengthening family-community connections, and this may be another reason for the limited and variable success of these interventions.

Finally, a fourth challenge to the effectiveness of home visitation is the need for clarity in program goals and expectations. In urging that practitioners and policymakers adopt more modest expectations for the success of home visiting programs, Gomby and colleagues (1999) offer a reminder that a home visitor cannot serve the needs of all families, and certainly cannot meet all the needs of troubled families. Complementing the efforts of a home visitor should be child-centered services (such as high-quality child care), parent-focused services using other approaches (such as parenting classes), and other strategies. Indeed, the need for other services that complement home visitation underscores the need for community embeddedness. Thus rather than attempting to increase the effectiveness of home visitation to address a wide range of goals, programs should be organized around a more focused set of objectives for home visitation and target other family needs through alternative service channels (Weiss, 1993). Home visitation programs which focus on limited, clear, well-defined, and realistic objectives have the greatest chance of success by enabling the program staff to sustain program focus, and to use limited resources to achieve realistic expectations (GAO, 1990).

\section{From Research to Social Policy and Back Again}

Program evaluation has inherent limitations, and these may be particular liabilities in the assessment of home visitation programs. When a general intervention strategy like home visitation is evaluated across programs with different goals and sites with different implementation challenges, it may be inevitable that only modest and inconsistent outcomes are found. This is especially likely for strategies, like home visitation, that are flexibly tailored by design to respond to the individual needs of recipient families. Many of the programs evaluated in the Gomby et al. (1999) report are early in their development and implementation, raising further questions about whether they were ready for a formal evaluation. Many of these limitations to program evaluation are especially true when meta-analytic strategies are used, because the typical criteria for statistical significance cannot substitute for clinical assessments of program impact.

Despite these caveats, there are significant lessons from these evaluation efforts for practitioners and policymakers. The training and support needs of home visitors deserve special consideration in light of the unique requirements and demands of their role, because the success of home visitation depends on whether those who provide social support are themselves supported. New approaches to training and inservice, and perhaps visitation in teams, warrant further examination. This highlights the need for adequate and reliable funding for home visitation programs because personnel costs are their most significant expense. Certainly the evaluation results indi- 
cate that it is difficult to conduct successful home visitation "on the cheap" with volunteer staff who receive limited training and continuing education. Another implication of the evaluation results is further consideration of how to better engage families in a home visitation program, perhaps by enlisting their participation earlier in the design of services and by attention to cultural and community mediators of their participation. It may also be necessary to consider whether certain kinds of families are better served by home visitation than others, since engagement may also be a function of the depth of the difficulties that family members face, their capacities to respond appropriately and competently to social support initiatives, and their interest in community involvement. In the context of focusing goals and expectations for what home visitation programs can accomplish, another implication of the evaluation findings is the need to recapture the goal of connecting families to neighborhood and community resources that can provide continuing assistance. For some home visitation programs, this may require a significant reorientation of how home visitors organize their efforts with target families.

These conclusions are relevant to social policy initiatives, like those of the U.S. Advisory Board on Child Abuse and Neglect, to create a "child-centered, neighborhood-based child protection system" relying, in part, on home visitation. Indeed, the evaluation results raise significant questions about this policy proposal. Is it an unduly expansive expectation that home visitation services would provide the basis for a neighborhood-based system of social support that could serve abuse prevention goals? If connecting families to community services is currently a weakness of home visitation programs, to what extent can a revitalized national home visitation system knit neighborhoods together as well as linking families to community agencies? Given that many of the families most at risk of child maltreatment are multiproblem families living in dangerous neighborhoods, to what extent is home visitation an effective strategy for reaching them? Are these families likely to become engaged in the services a home visitor can provide? Are their neighborhoods sufficiently rich with human and material resources to provide avenues of continuing social support, or are these instead neighborhoods drained of resources that most families seek to flee? If the latter is true, is it necessary to reconstitute communities before home visitation can function effectively?

These questions illustrate the challenges of moving from social support theory to home visitation applications to social policy implications. As scientists concerned with child and family well-being move to increasing levels of specificity, the practical problems of implementing social support initiatives help to clarify the gaps in conceptual analysis. As a consequence, new questions emerge for the further study of social support. How do community conditions influence the nature of social support and its effects? What are the psychological resources required of an individual who provides social support? What can social support reasonably be expected to offer a troubled individual - and what are the limits of its therapeutic or preventive effects?

These questions also exemplify the proper uses of evaluation research. It is best to regard the current evaluations of home visitation programs as formative evaluations that are intended to improve program design and service delivery. Unfortunately, evaluations are more commonly regarded by funding agencies and policymakers as summative evaluations that are intended to provide guidance concerning whether further investment in a promising intervention strategy is warranted. Because of the confusion between the nature and purposes of formative and summative program evaluation, it is common for advocates of promising intervention programs to be anxious about evaluation research, to seek to defend their programs against potentially negative evaluation results, and, indeed, to influence the design of evaluation studies to yield the most optimistic conclusions about the program's overall benefits and value. In our view, this failure to distinguish formative from summative evaluation can undermine the benefits of evaluation studies, especially for developing intervention strategies like home visitation. More specifically, if the cur- 
rent evaluations of home visitation programs are interpreted as summative, leading to the withdrawal of public interest and funding from home visitation initiatives, it could have disastrous consequences for the future of intervention strategies involving social support. We urge instead the investment of research funds to further explore how visitation programs can be revised based on these evaluation results so that the next generation of home visitation programs are stronger, more focused, and yield greater benefits for families. Doing so would provide a model for how evaluation studies can contribute to the improvement of promising intervention strategies, rather than (often premature) decisions concerning their potential benefits.

\section{Future Research Directions}

One of the most important features of the social support literature is how basic research is relevant to applied programs and to public policy concerns, and how, in turn, the results of evaluation studies and policy analyses raise new questions for basic research into social support processes. There is, in short, a significant convergence of basic, applied, and policy questions concerning social support. In this spirit, we believe that this discussion has raised new questions for future research about the natural and formal support processes that individuals commonly experience, and about the future of home visitation programs.

With respect to everyday processes of social support, it is important to understand the following:

- How do natural networks of social support function in everyday life? How is their functioning influenced by aspects of neighborhood and community life that may inhibit or encourage contact with others? How are they affected by cultural values?

- How do individuals experience support from informal and formal helpers in everyday life? How do they identify particular persons as sources of reliable assistance, and what are the characteristics of these people?
- What do parents perceive as their greatest needs concerning social support? Which of these needs can be best served by a formal help provider (like a home visitor) and which by another kind of helper?

- How does stress, family turmoil, or the psychological problems of a family member affect social support processes within families? What causes some families to seek and gratefully accept assistance from others and other families to become withdrawn and isolated? What are the characteristics of potential help providers that may affect how families respond to offered aid?

- What are the novel avenues by which formal and informal sources of support to family members can be harmonized?

With respect to home visitation programs, there are equally interesting questions for future study:

- What kinds of families are most likely to benefit from a home visitor? For what kinds of families is home visitation unnecessary or unhelpful?

- Who chooses to participate in a home visitation program? Why do they do so? What do they want? What are their expectations of what will happen?

- Who chooses to discontinue participation in home visitation? Why do they do so?

- What happens during a typical encounter between a home visitor and a parent? Why do some home visitors depart so significantly from the curricula of their program models? What do family members experience during a typical session?

- What is the frequency of contact with a home visitor, and duration of services, that best serves needy families? How is the answer to this question contingent on family circumstances, the needs of family members, and the goals of home visitation?

- How can home visitors be better assisted? What creative approaches to home visitation can reduce their stress and burnout? 
- What are the problems typically encountered when model home visitation programs (or other forms of social support intervention) are "scaled up" to become broadly implemented intervention programs?

These do not exhaust, of course, the range of questions posed by the research reviewed in this paper. There illustrate, however, the broad variety of questions remaining for basic theory concerning social support, applied research concerning home visitation, and public policy concerning the treatment and prevention of child and family problems.

\section{Conclusion}

This discussion of social support underscores how important are relationships to well-being. The research on social support shows how significantly the guidance, counseling, information, material aid, and emotional assistance of others can promote psychological healing and prevent dysfunctional responses to stress, especially when stress arises from difficulties in other close relationships. At the same time, this literature also highlights how complex are human relationships, and that characteristics of both the provider and recipient of social support are crucial mediators of its influence. These studies show how multidimensional and, at times, inconsistent are the human needs served by social support, which can make both providers and recipients of support ambivalent about their relationship.

\section{References}

Albano, A. M., Chorpita, B. F., \& Barlow, D. H. (1996). Childhood anxiety disorders. In E. J. Mash \& R. A. Barkley (Eds.), Child psychopathology (pp. 196241). New York: Guilford.

Appelbaum, M., \& Sweet, M. A. (1999, March). Is home visiting an effective strategy? Paper presented at a Workshop on Revisiting Home Visiting, sponsored by the Board on Children, Youth, and Families of the National Research Council/Institute of Medicine, Washington, DC.

Baker, A. J. L., Piotrkowski, C. S., \& Brooks-Gunn, J. (1999). The Home Instruction Program for Preschool Youngsters (HIPPY). The Future of Children, 9, 116-133.

Barnes, H., Goodson, B., \& Layzer, J. (1995, 1996). Re-
When this research is applied to interventions like home visitation, it is not surprising that programmatic efforts to provide social support to troubled families are easy to envision but difficult to implement. If the results of the initial evaluation studies of home visitation programs are "sobering," it is because the expectations for the initial generation of these programs were not carefully guided by research on social support and the complexities of human relationships. Instead, promising early findings concerning the benefits of a home visitor for troubled families led to the ambitious expectation that statewide or national home visitation programs could curb child maltreatment, improve parent-child relationships, reconstitute neighborhoods, and strengthen community support for families and their children.

Having learned that these expansive expectations are unwarranted, the current moment is a delicate one for the future of social support initiatives. It is possible that policymakers may conclude, as they often done so frequently in the past, that the initial promise of home visitation was unwarranted and that research and program funding should be reallocated elsewhere. We believe that a far wiser course would be to recapture the realization that addressing complex problems of developmental psychopathology through the complex dynamics of human relationships will take further study, the fine-tuning of intervention strategies, and an enduring commitment to understanding how best to help troubled families and their children.

view of research on supportive interventions for children and families (Vols. I and II). Cambridge, MA: Abt Associates.

Belle, D. (1982). Social ties and social support. In D. Belle (Ed.), Lives in stress (pp. 133-144). Beverly Hills, CA: Sage.

Berscheid, E., \& Reis, H. (1998). Attraction and close relationships. In D. T. Gilbert, S. T. Fiske, \& G. Lindzey (Eds.), Handbook of social psychology (4th ed., pp. 193-281). New York: McGraw-Hill.

Bowlby, J. (1988). A secure base. New York: Basic Books.

Carter, L. S., Weithorn, L. A., \& Behrman, R. E. (1999). Domestic violence and children: Analysis and recommendations. The Future of Children, 9(3), 4-20.

Cicchetti, D., \& Toth, S. L. (1995). Developmental psy- 
chopathology and disorders of affect. In D. Cicchetti \& D. J. Cohen (Eds.), Developmental psychopathology: Vol. 2. Risk, disorder, and adaptation (pp. 369-420). New York: Wiley.

Cochran, M., Larner, M., Riley, D., Gunnarsson, L., \& Henderson, C. R. (Eds.). (1990). Extending families: The social networks of parents and their children. Cambridge: Cambridge University Press.

Cohen, S., \& Wills, T. A. (1985). Stress, social support, and the buffering hypothesis. Psychological Bulletin, 98, 310-357.

Collins, A. H., \& Pancoast, D. L. (1976). Natural helping networks: A strategy for prevention. Washington, DC: National Association of Social Workers.

Collins, W. A., \& Laursen, B. (Eds.). (1999). Minnesota Symposia on Child Psychology: Vol. 30. Relationships as developmental contexts. Mahwah, NJ: Erlbaum.

Cowan, P. A., Powell, D., \& Cowan, C. P. (1998). Parenting interventions: A family systems perspective. In W. Damon (Series Ed.) \& I. E. Sigel \& K. A. Renninger (Vol. Eds.), Handbook of child psychology: Vol. 4. Child psychology in practice (5th ed., pp. 3-72). New York: Wiley.

Cummings, E. M., \& Davies, P. (1994). Children and marital conflict: The impact of family dispute and resolution. New York: Guilford.

Daro, D. (in press). Child abuse prevention: New directions and challenges. In D. J. Hansen (Ed.), Nebraska Symposium on Motivation: Vol. 46. Motivation and child maltreatment. Lincoln, NE: University of Nebraska Press.

Daro, D. A., \& Harding, K. A. (1999). Healthy Families America: Using research to enhance practice. The $\mathrm{Fu}$ ture of Children, 9, 152-176.

Davies, P. T., \& Cummings, E. M. (1994). Marital conflict and child adjustment: An emotional security hypothesis. Psychological Bulletin, 116, 387-411.

Dawson, G., Hessl, D., \& Frey, K. (1994). Social influences on early developing biological and behavioral systems related to risk for affective disorder. Development and Psychopathology, 6, 759-779.

Dishion, T. J., French, D. C., \& Patterson, G. R. (1995). The development and ecology of antisocial behavior. In D. Cicchetti \& D. J. Cohen (Eds.), Developmental psychopathology: Vol. 2. Risk, disorder, and adaptation (pp. 421-471). New York: Wiley.

Duggan, A. K., McFarlane, E. C., Windham, A. M., Rohde, C. A., Salkever, D. S., Fuddy, L., Rosenberg, L. A., Buchbinder, S. B., \& Sia, C. C. J. (1999). Evaluation of Hawaii's Healthy Start Program. The Future of Children, 9, 66-90.

Eckenrode, J. (1983). The mobilization of social supports: Some individual constraints. American Journal of Community Psychology, 11, 509-528.

Eckenrode, J., \& Wethington, E. (1990). The process and outcome of mobilizing social support. In S. Duck (Ed.), Personal relationships and social support (pp. 83-103). London: Sage.

Edelson, J. L. (1999). Children's witnessing of adult domestic violence. Journal of Interpersonal Violence, 14, 839-870.

Fisher, J. D., Nadler, A., \& Witcher-Alagna, S. (1982). Recipient reactions to aid. Psychological Bulletin, 91, 27-54.

Froland, C., Pancoast, D. L., Chapman, N. J., \& Kimboko, P. J. (1981). Linking formal and informal support systems. In B. H. Gottlieb (Ed.), Social networks and social support (pp. 259-275). Beverly Hills, CA: Sage.

Garbarino, J., \& Sherman, D. (1980). High-risk neighborhoods and high-risk families: The human ecology of child maltreatment. Child Development, 51, 188-198.

Gaudin, J. M., Wodarski, J. S., Arkinson, M. K., \& Avery, L. S. (1990-1991). Remedying child neglect: Effectiveness of social network interventions. Journal of Applied Social Sciences, 15, 97-123.

General Accounting Office (GAO). (1990). Home visiting: A promising early intervention strategy for atrisk families (GAO/HRD-90-83). Washington, DC: Government Printing Office.

Goldstein, M. (1987). Psychosocial issues. Schizophrenia Bulletin, 13, 157-171.

Gomby, D. S., Culross, P. L., \& Behrman, R. E. (1999). Home visiting: Recent program evaluations-Analysis and recommendations. The Future of Children, 9, 4-26.

Gottlieb, B. (1983). Social support strategies. Beverly Hills, CA: Sage.

Gottlieb, B. (1985). Theory into practice: Issues that surface in planning interventions which mobilize support. In I. G. Sarason \& B. R. Sarason (Eds.), Social support: Theory, research, and applications (pp. 417-437). The Hague: Martinus Nijhoff.

Greenberg, M. S., \& Westcott, D. R. (1983). Indebtedness as a mediator of reactions to aid. In J. D. Fisher, A. Nadler, \& B. M. DePaulo (Eds.), New directions in helping: Vol. 1. Recipient reactions to aid (pp. 85112). New York: Academic.

Guralnick, M. J. (Ed.). (1997). The effectiveness of early intervention. Baltimore, MD: Paul H. Brookes.

Halpern, R. (2000). Early childhood intervention for low income children and families. In J. P. Shonkoff \& S. J. Meisels (Eds.), Handbook of early childhood intervention (2nd ed.). New York: Cambridge University Press.

Hart, S. N., Brassard, M. R., \& Karlson, H. C. (1996). Psychological maltreatment. In J. Briere, L. Berliner, J. A. Bulkey, C. Jenny, \& T. Reid (Eds.), The ABSAC handbook of child maltreatment (pp. 72-89). Thousand Oaks, CA: Sage.

Hawaii Department of Health. (1992). Healthy Start: Hawaii's system of family support services. Honolulu: Author.

Heller, K., \& Swindle, R. W. (1983). Social networks, perceived social support, and coping with stress. In R. D. Felner, L. A. Jason, J. N. Moritsugu, \& S. S. Farber (Eds.), Preventive psychology: Theory, research, and practice (pp. 87-103). New York: Pergamon.

Hirshfeld, D. R., Rosenbaum, J. F., Smoller, J. W., Fredman, S. J., \& Bulzacchelli, M. T. (1998). Early antecedents of panic disorder: Genes, childhood, and the environment. In J. F. Rosenbaum \& M. H. Pollack (Eds.), Panic disorder and its treatment (pp. 93-151). New York: Marcel Dekker.

House, J. H., Umberson, D., \& Landis, K. R. (1988). Structures and processes of social support. In W. R. Scott \& J. Blake (Eds.), Annual review of sociology (Vol. 14, pp. 293-318). Palo Alto, CA: Annual Reviews.

Kavanagh, D. J. (1992). Recent developments in expressed emotion and schizophrenia. British Journal of Psychiatry, 160, 601-620.

Korbin, J. E. (1989). Fatal maltreatment by mothers: A proposed framework. Child Abuse \& Neglect, 13, 481-489. 
Korbin, J. E. (1995). Social networks and family violence in cross-cultural perspective. In G. B. Melton (Ed.), Nebraska Symposium on Motivation: Vol. 42. The in dividual, the family, and social good: Personal fulfillment in times of change (pp. 107-134). Lincoln, NE: University of Nebraska Press.

Larner, M., Halpern, R., \& Harkavy, O. (Eds.). (1992). Fair start for children: Lessons learned from seven demonstration projects. New Haven, CT: Yale University Press.

Margie, N. G., \& Phillips, D. (1999). Revisiting home visiting: Summary of a workshop. Washington, DC: National Academy of Sciences Press.

Masten, A. S., \& Coatsworth, J. D. (1995). Competence, resilience, and psychopathology. In D. Cicchetti \& D. J. Cohen (Eds.), Developmental psychopathology: Vol. 2. Risk, disorder, and adaptation (pp. 715-752). New York: Wiley.

Melton, G. B., Thompson, R. A., \& Small, M. A. (Eds.) (in press). Toward a child-centered, neighborhoodbased child protection system: A report of the Consortium on Children, Families, and the Law. Westport, CT: Praeger.

Miller, J. L., \& Whittaker, J. K. (1988). Social services and social support: Blended programs for families at risk for child maltreatment. Child Welfare, 67, 161-174.

O'Donnell, L., \& Steuve, A. (1983). Mothers as social agents: Structuring the community activities of school aged children. In H. Lopata \& J. H. Pleck (Eds.), Research on the interweave of social roles: Jobs and families: Vol. 3. Families and jobs (pp. 113-129). Greenwich, CT: JAI Press.

Olds, D. L. (1988). The Prenatal/Early Infancy Project. In R. H. Price, E. L. Cowen, R. P. Lorion, \& J. Ramos-McKay (Eds.), 14 ounces of prevention: A casebook for practitioners (pp. 9-23). Washington, DC: American Psychological Association.

Olds, D. L., Henderson, C. R., Kitzman, H. J., Eckenrode, J. J., Cole, R. E., \& Tatelbaum, R. C. (1999). Prenatal and infancy home visitation by nurses: Recent findings. The Future of Children, 9, 44-65.

Olds, D. L., \& Kitzman, H. (1990). Can home visitation improve the health of women and children at environmental risk? Pediatrics, 86, 108-116.

Olds, D. L., \& Kitzman, H. (1993). Review of research on home visiting for pregnant women and parents of young children. The Future of Children, 3, 53-92.

Parke, R. D., \& Bhavnagri, N. P. (1989). Parents as managers of children's peer relationships. In D. Belle (Ed.), Children's social networks and social supports (pp. 241-259). New York: Wiley.

Patterson, G. R., DeBaryshe, B. D., \& Ramsey, E. (1989). A developmental perspective on antisocial behavior. American Psychologist, 44, 329-335.

Patterson, G. R., Reid, J. B., \& Dishion, T. J. (1992). Antisocial boys. Eugene, OR: Castalia.

Polansky, N. A., Chalmers, M. A., Buttenwieser, E., \& Williams, D. P. (1981). Damaged parents: An anatomy of child neglect. Chicago: University of Chicago Press.

Robinson, N. S., \& Garber, J. (1995). Social support and psychopathology across the life span. In D. Cicchetti \& D. J. Cohen (Eds.), Developmental psychopathology: Vol. 2. Risk, disorder, and adaptation (pp. 162-209). New York: Wiley.

Seagull, E. A. W. (1987). Social support and child maltreatment: A review of the evidence. Child Abuse \& Neglect, 11, 41-52.

Shaw, D. S., Keenan, K., \& Vondra, J. I. (1994). Devel- opmental precursors of externalizing behavior: Ages 1 to 3. Developmental Psychology, 30, 355-364.

Shaw, D. S., Owens, E. B., Vondra, J. I., Keenan, K., \& Winslow, E. B. (1996). Early risk factors and pathways in the development of early disruptive behavior problems. Development and Psychopathology, 8, 679-699.

Shinn, M., Lehmann, S., \& Wong. N. W. (1984). Social interaction and social support. Journal of Social Issues, 40, 55-76.

Shumaker, S. A., \& Brownell, A. (1984). Toward a theory of social support: Closing conceptual gaps. Journal of Social Issues, 40, 11-36.

St. Pierre, R. G., \& Layzer, J. I. (1999). Using home visits for multiple purposes: The Comprehensive Child Development Program. The Future of Children, 9, 134-151.

Thompson, R. A. (1995). Preventing child maltreatment through social support: A critical analysis. Thousand Oaks, CA: Sage.

Thompson, R. A. (in press). Childhood anxiety disorders from the perspective of emotion regulation and attachment. In M. W. Vasey \& M. R. Dadds (Eds.), The developmental psychopathology of anxiety. Oxford: Oxford University Press.

Thompson, R. A., \& Calkins, S. (1996). The doubleedged sword: Emotional regulation for children at risk. Development and Psychopathology, 8, 163-182.

Thompson, R. A., Flood, M. F., \& Lundquist, L. (1995). Emotional regulation: Its relations to attachment and developmental psychopathology. In D. Cicchetti \& S. L. Toth (Eds.), Rochester Symposium on Developmental Psychopathology: Vol. 6. Emotion, cognition, and representation (pp. 261-299). Rochester, NY: University of Rochester Press.

Thompson, R. A., \& Wyatt, J. M. (1999). Current research on child maltreatment: Implications for educators. Educational Psychology Review, 11, 173-201.

U.S. Advisory Board on Child Abuse and Neglect. (1991). Creating caring communities: Blueprint for an effective federal policy on child abuse and neglect. Washington, DC: Government Printing Office.

U.S. Advisory Board on Child Abuse and Neglect. (1993a). The continuing child protection emergency: A challenge to the nation. Washington, DC: Government Printing Office.

U.S. Advisory Board on Child Abuse and Neglect. (1993b). Neighbors helping neighbors: A new national strategy for the protection of children. Washington, DC: Government Printing Office.

Vaux, A. (1988). Social support: Theory, research, and intervention. New York: Praeger.

Wagner, M. M., \& Clayton, S. L. (1999). The Parents as Teachers Program: Results from two demonstrations. The Future of Children, 9, 91-115.

Wasik, B. H., Bryant, D. M., \& Lyons, C. M. (1990), Home visiting. Newbury Park, CA: Sage.

Wasik, B. H., \& Roberts, R. N. (1994). Survey of home visiting programs for abused and neglected children and their families. Child Abuse \& Neglect, 18, 271283.

Weiss, H. (1993). Home visits: Necessary but not sufficient. The Future of Children, 3, 113-128.

Zahn-Waxler, C., \& Kochanska, G. (1990). The origins of guilt. In R. Thompson (Ed.), Nebraska Symposium on Motivation: Vol. 36. Socioemotional development (pp. 183-258). Lincoln, NE: University of Nebraska Press. 